\title{
VICENTE SEABRA TELLES E A CRIAÇÃO DA NOMENCLATURA EM PORTUGUÊS PARA A QUÍMICA 'NOVA' DE LAVOISIER
}

\author{
Fernando J. Luna
}

Centro de Ciência e Tecnologia, Universidade Estadual do Norte Fluminense, Av. Alberto Lamego, 2000, 28013-602 Campos dos Goytacazes - RJ, Brasil

Recebido em 31/7/12; aceito em 5/11/12; publicado na web em 12/3/13

\begin{abstract}
VICENTE SEABRA TELLES TRANSLATES LAVOISIER'S REFORMED CHEMICAL NOMENCLATURE INTO PORTUGUESE. In 1787, Lavoisier and coworkers published a 314-page book entitled Méthode de nomenclature chimique in which a novel system for the naming of compounds and elements was presented. The Brazilian chemist Vicente Coelho de Seabra Telles (1764-1804) was responsible for translating it into Portuguese. Telles proposed the adoption not only of the Latin etymology, but decided to use Latin suffixes as well, because of the similarity between Latin and the Portuguese language. In doing so, he made the names of the compounds in Portuguese bear a closer resemblance to the names in Latin than to those in French or Spanish.
\end{abstract}

Keywords: history of chemistry; science in Brazil; nomenclature.

\section{INTRODUÇÃO}

Na história do pensamento e da cultura no Ocidente, o período entre meados do século XVII até o fim do século XVIII, denominado Iluminismo, caracteriza-se por mudanças radicais na ciência, na filosofia, na sociedade e na política. Nessa época, uma série de revoluções aniquilou de vez a mentalidade medieval e lançou as bases que definem o mundo ocidental moderno. ${ }^{1}$ Historicamente, o pensamento iluminista culminou na agitação política da Revolução Francesa, ocasião em que a ordem hierárquica política e social tradicional foi destruída subitamente e substituída, naquele país, por uma ordenação sociopolítica baseada nos ideais iluministas de liberdade e igualdade, de acordo com os princípios da razão humana. ${ }^{2}$

As ideias do Iluminismo rapidamente se espalharam pela Europa, principalmente por meio impresso. A publicação da monumental Encyclopédie de Diderot, com 28 volumes, com a ambição de conter todo o conhecimento humano explicado na forma de verbetes era a mais eloquente expressão dos ideais dos iluministas. As elites educadas em toda a Europa liam não somente a Encyclopédie, mas também toda sorte de panfletos curtos sobre uma miríade de assuntos, apresentados de forma didática e com base científica de acordo com o objetivo do projeto iluminista - a saber- espalhar o conhecimento a fim de fazer a humanidade emergir da situação de imaturidade em que se encontrava, como explicou Kant em $1784 .^{3}$

Em Portugal e no Brasil, o que mais contribuiu para a disseminação do Iluminismo foi a reforma pombalina da Universidade de Coimbra, em 1772, com a contratação de professores estrangeiros para ensinar as ciências naturais na recém-criada Faculdade de Filosofia. Essas mudanças repercutiram rapidamente na colônia porque, durante todo o século XVIII, houve um fluxo constante de filhos da aristocracia brasileira em direção a Coimbra para fazer os estudos universitários, não somente em Direito ou Teologia, mas também Medicina ou frequentar o recém-criado curso de Filosofia Natural, que incluía matérias como zoologia, botânica, mineralogia, física e um ano inteiro dedicado à química.

Não menos importante foi a política do governo português de promover a tradução e publicação de livros e panfletos oriundos principalmente da França e Inglaterra. Nessa empreitada, os brasileiros

*e-mail: fernando@uenf.br tiveram um papel central, principalmente trabalhando na editora do Arco do Cego ao final da última década do século XVIII. A Tipografia do Arco do Cego, assim chamada por sua localização nos arredores da Lisboa setecentista, foi fundada por José Mariano da Conceição Veloso (1741-1811) em 1799, com a missão de traduzir e publicar a literatura científica relevante disponível no resto da Europa que pudesse ser útil para o avanço da indústria e da agricultura de Portugal e das colônias. ${ }^{4}$

Um dos livros publicados nessa editora foi uma versão do Méthode de nomenclature chimique, ${ }^{5}$ escrito por Lavoisier em cooperação com Louis Guyton de Morveau (1837-1816), Claude Berthollet (1748-1822) e Antoine de Fourcroy (1755-1809), em 1787. Nessa obra, os autores apresentavam um esquema sistemático em que as substâncias químicas foram renomeadas de forma a melhor se acomodar com a nova teoria antiflogística. O livro foi determinante para a disseminação e sustentação da nova química — cujas bases teóricas perduram até os dias atuais — porque lançava os princípios de um sistema para dar nomes às substâncias químicas e se propunha a substituir as múltiplas nomenclaturas que coexistiam até então.

Neste artigo, o objetivo foi discutir alguns aspectos concernentes à introdução da nomenclatura lavoisiana na língua portuguesa por meio da análise do Méthode de nomenclature chimique, parcialmente traduzido para o português pelo químico brasileiro Vicente Coelho de Seabra Silva e Telles (1764-1804).

\section{A LINGUAGEM DA NOVA QUÍMICA}

A unificação e sistematização da nomenclatura foi um dos aspectos mais importantes da revolução química liderada pelos franceses, que conseguiram eliminar os confusos e díspares nomes dados às substâncias e aos elementos químicos. 'Sal de Glauber' e 'vitríolo de soda' eram dois nomes dados ao sulfato de sódio, por exemplo. Já o sulfato de ferro tinha quatro denominações diferentes: 'vitríolo marcial', 'vitríolo verde', 'sal de colcothar' e 'capa rosa verde'. Com o sulfato de magnésio, a nomenclatura era mais confusa ainda, pois podia ser denominado 'sal de Epsom', 'sal de Sedlitz', 'sal de Steidschutz', 'sal cathartico amargo' ou 'vitríolo magnesiano'. Partindo das ideias gestadas pelos químicos franceses, foi possível estabelecer um padrão que seria adotado pelo resto do mundo. $\mathrm{O}$ próprio Lavoisier aponta que os nomes 
óleo de tártaro por desfalecimento, óleo de vitriol, manteiga de arsênio e de antimônio, flores de zinco, etc. são ainda mais ridículos, pois têm origem em ideias falsas; porque não existem propriamente no reino mineral e, sobretudo, no reino metálico, nem manteigas, nem óleos nem flores; $e$, ainda, porque as substâncias designadas por estes nomes enganadores são venenos poderosos. ${ }^{6}$

Uma vez que não havia um sistema único convencionado para designar os compostos, que eram nomeados ao acaso por estudiosos em diferentes países à medida que eram identificados, analisados e descritos, múltiplos nomes para um mesmo composto foram surgindo com o tempo, o que dificultava o trabalho de memória, a leitura de livros de química e mesmo a comunicação entre os homens de ciência. Os autores da nova nomenclatura buscaram radicais gregos para criar os nomes dos novos compostos, que deviam dar alguma indicação sobre as propriedades da substância designada. Usando este método, os compostos recém-descobertos podiam imediatamente receber um único nome, independente das escolhas arbitrárias que haviam norteado a nomenclatura até então.

A nova linguagem da química não foi uma criação ex nihilo. Como explica Lavoisier, uma nomenclatura baseada em princípios sistemáticos já vinha sendo engendrada por Pierre-Joseph Macquer (1718-1784) e Antoine Baumé (1728-1804):

É a eles que se deve principalmente haverem designado os sais metálicos pelo nome do ácido e do metal que entram na sua composição; de haverem classificado sob o nome de vitríolo todos os sais resultantes da dissolução de uma substância metálica em ácido vitriólico $[\ldots]^{7}$

Outro passo em direção a uma nomenclatura reformada foi dado por Torbern Bergman (1735-1784) com a publicação de Sciagraphia regni mineralis, livro cuja tradução para o português também seria publicada pela editora do Arco do Cego. ${ }^{8}$ Professor na Universidade de Uppsala e um dos químicos mais influentes da Europa setecentista, Bergman propôs uma reforma tratando especialmente dos sais, que deveriam ganhar nomes binários em latim, inspirado na nomenclatura binomial lineana para o reino vegetal. Logo em seguida, e sob sua influência, o francês Guyton de Morveau publicava suas propostas para reformar a nomenclatura, tendo o cuidado de convocar seus contemporâneos para contribuir com críticas. A reforma era baseada em cinco princípios sobre os quais uma nomenclatura verdadeiramente sistemática pudesse ser erigida. Junto com o artigo, publicou também uma grande tabela contendo exemplos dos nomes que propugnava. ${ }^{9}$

Em seus escritos, o grupo de Lavoisier dedicou-se a advogar pela ideia de que uma ciência renovada, como a nova química nascente, necessitava de uma nova linguagem capaz de exprimir os seus conceitos com a clareza que se aproximasse ao máximo possível do que a linguagem matemática lograva fazer, baseando-se nas ideias do filósofo Etienne Bonnet de Condillac (1714-1780), que defendia o caráter algébrico de todo o raciocínio humano e que, portanto, o aperfeiçoamento do raciocínio somente poderia ser alcançado pelo aperfeiçoamento da linguagem. No trecho abaixo, Lavoisier explica o pensamento de Condillac:

A álgebra é o método analítico par excellence: foi projetada para facilitar as operações da mente, para encurtar o curso do raciocínio, para reforçar, com poucas linhas, o que teria exigido um grande número de páginas de discussão $e$, finalmente, levar a uma solução mais conveniente, rápida e segura para questões muito complicadas. [...] a álgebra é uma linguagem real: como todas as línguas, tem seus sím- bolos representativos, o seu método e sua gramática [...] Assim um método analítico é uma língua [e] uma língua é um método analítico e essas duas expressões são, em certo sentido, sinônimas. ${ }^{10}$

Com efeito, a tortuosa linguagem da química que existia até então havia sido criada por alquimistas, cujo objetivo não era o de se fazer entender-muito pelo contrário, "eles se serviam de uma linguagem enigmática que lhes era particular, que na maioria das vezes tinha um sentido para os adeptos e outro para o [leitor] comum..."11

Mas Lavoisier não se contentou em atacar somente os alquimistas e acusava também os químicos modernos, ou 'sistemáticos', como ele os chamava para diferenciá-los dos alquimistas, de desconsiderar "um número de fatos que não se encaixavam em suas ideias e de distorcer, de alguma forma, os [fatos] que estavam dispostos a manter [...] de sorte que a ciência, em suas mãos, é somente um edifício construído por sua imaginação". ${ }^{12}$

O livro Méthode de nomenclature chimique consiste de uma coleção de monografias, além do dicionário de química. Como mostra a Tabela 1, as três memórias introdutórias são seguidas por dois glossários, que formam o núcleo do livro. No primeiro glossário, intitulado 'sinonímia antiga e nova', são listados os nomes tradicionais dos compostos e dos elementos em ordem alfabética - cada um seguido do seu correspondente de acordo com a nova nomenclatura sendo proposta. No segundo léxico, são listados os nomes novos em francês e em latim, seguidos dos nomes correspondentes tradicionais. A monografia que se encontra depois dos glossários foi, curiosamente, escrita por defensores da teoria do flogisto. ${ }^{13}$ Dois jovens alunos de Lavoisier, Jean-Henri Hassenfratz (1755-1827) e Pierre-Auguste Adet (1763-c.1832) foram os responsáveis pela criação dos símbolos para os elementos químicos em que os metais são representados por letras maiúsculas dentro de um círculo. ${ }^{14} \mathrm{~A}$ última seção do livro é assinada pelos três autores principais.

Tabela 1. Visão geral do livro Méthode de nomenclature chimique, de 1787

\begin{tabular}{ll}
\hline Autor & Título da seção \\
\hline Lavoisier & Monografia sobre a necessidade reformar e aperfeiçoar \\
& a nomenclatura química (Mémoire sur la nécessité de \\
& réformer \& de perfectionner la nomenclature chimique)
\end{tabular}

de Morveau Monografia sobre o desenvolvimento dos princípios da nomenclatura metódica (Mémoire sur le développement des principes de la Nomenclature méthodique)

Fourcroy Monografia para servir à explicação da tabela de nomenclatura (Mémoire pour servir à l'explication du tableau de nomenclature)

Sinonímia antiga e nova, por ordem alfabética (Synonimie ancienne \& nouvelle, par ordre alphabétique)

Dicionário para a nova nomenclatura química (Dictionnaire pour la nouvelle nomenclature chimique)

Baumé, Cadet, Relatório sobre a nova nomenclatura (Rapport sur la nouDarcet e Sage velle nomenclature)

Hassenfratz e Monografia sobre os novos símbolos a empregar em quíAdet mica (Mémoires sur des nouveaux caractères à employer en chimie)

Bertholet Four- Relatório sobre os novos símbolos químicos (Rapport sur croy e Lavoisier les nouveaux caractères chimiques)

A nova química espalhou-se rapidamente pelo mundo ocidental graças à disseminação do Méthode de nomenclature chimique — até 1805, sete edições desta obra apareceram na França, e foi traduzido para o inglês, alemão, italiano e espanhol — e também graças ao 
livro Traité élémentaire de chimie, publicado por Lavoisier em 1789, contendo ilustrações desenhadas por sua esposa, que foi ainda mais bem recebido do que a primeira obra. Deste livro, houve nove edições em francês, cinco inglesas, três em alemão, duas em holandês, três em italiano, uma na Espanha, três estadunidenses e uma mexicana, todas publicadas antes de $1805 .{ }^{15}$

Portugal e sua colônia americana acompanharam pari passu os outros países europeus na recepção da nova química, à medida que era engendrada pelo grupo liderado por Lavoisier. Na Tabela 2, são listadas as traduções da nomenclatura da nova química, estabelecida em 1787 em Paris, para as diversas línguas europeias. Para a língua portuguesa, quem fez a tradução do novo sistema de dar nomes aos elementos e compostos químicos foi Vicente Seabra Telles, ${ }^{20}$ no livro intitulado Nomenclatura chimica portugueza, franceza, e latina.

Tabela 2. Traduções coevas do Méthode de nomenclature chimique para línguas europeias

\begin{tabular}{cccc}
\hline Ano & País ou língua & Responsável & Ref./observações \\
\hline 1788 & Espanha & Pedro Gutierrez Bueno & 16 \\
1788 & Inglaterra & James St. John & 17 \\
1789 & Itália & $?$ & em versão resumida \\
1790 & Portugal & Vicente Seabra Seabra Telles & $c f$. Figura 1 \\
1791 & E.U.A. & Thomas Dobson & 18 \\
1793 & alemão & Karl von Meidinger & Em ref. 15, p. 194 \\
1795 & Suécia & A. G. Ekeberg e P. Afzelius & 19 \\
\hline
\end{tabular}

Seabra Telles foi para a Universidade de Coimbra em 1783, após ter recebido sua educação inicial no Brasil, que deve ter incluído o latim e o grego, já que exames obrigatórios dessas línguas eram requisitos para admissão. Em 1787, recebeu o diploma de bacharel em filosofia. ${ }^{21} \mathrm{O}$ curso de 4 anos de Filosofia consistia das disciplinas de lógica, metafísica e moral no $1^{\circ}$ ano, zoologia, botânica e mineralogia, durante o $2^{\circ}$ ano e, em seguida, física e química no $3^{\circ}$ e $4^{\circ}$ anos, respectivamente. ${ }^{22}$ Logo depois, Seabra Telles ingressou no curso de Medicina, concluído em $1791 .^{23}$

Seabra Telles escreveu pelo menos treze livros ou memórias científicas. ${ }^{24}$ Sua mais importante obra foi o livro-texto Elementos de Chimica, um calhamaço de quase 500 páginas dividido em duas partes, publicado em Coimbra. Este livro é considerado o primeiro compêndio de Química escrito por um brasileiro. ${ }^{25} \mathrm{~A}$ obra foi publicada em duas partes: a primeira em 1788 , ou seja, um ano antes que Lavoisier publicasse o Traité élémentaire de chimie, de 1789, cujo conteúdo apresentava a síntese da sua teoria e foi fundamental na luta contra a teoria do flogisto. A segunda parte da obra apareceu em 1790.

Entretanto, como explica António Amorim da Costa, “o impacto do compêndio de Seabra em Portugal foi pequeno, apesar da Congregação da Faculdade de Filosofia da Universidade de Coimbra ter dado a sua aprovação, em 1787, e a autorização de publicação, em 1788. Todavia, não há o menor indício de que os Elementos de Chimica tenham alguma vez sido adoptados pela Universidade". ${ }^{26}$ Amorim da Costa também explica que Thomé Rodrigues Sobral (1759-1829), professor de química em Coimbra por longos anos, planejou sua própria publicação sobre nomenclatura, mas deve ter desistido uma vez que já existia a de Seabra Telles. ${ }^{27}$

É na introdução do livro Elementos de chimica onde Seabra Telles justifica sua conversão à nova nomenclatura, afirmando que

"nós a adoptamos não levados pela novidade, como alguns julgarão, mas persuadidos da sua utilidade real, e a accommodamos de modo possível ao idiotismo da nossa lingoagem, da latina, e Franceza, de sorte que se evitasse qualquer confusão, que pode haver na mesma adopção. He verdade, que parece duro deixar alguns nomes triviaes, $e$ entre nós tão usados para substituir-lhes outros novos, ou menos usados: porém isso he preciso quando as palavras não dão a conhecer a natureza dos corpos que nomeão. A lingoagem das Sciencias he muito differente da do povo. Com tudo temos a cautela de ajuntar às palavras novas os seus synonimos até aqui usados." 28

Na Nomenclatura..., cuja página de rosto é mostrada na Figura 1, Seabra Telles lançou as bases da maneira como os químicos iriam se expressar em língua portuguesa pelos dois séculos que se seguiram à sua publicação. A ele se deve a adoção da etimologia latina na criação dos nomes de compostos e elementos químicos, uma escolha que viria a ser respeitada 20 anos depois por Luís da Silva Mousinho de Albuquerque (1792-1846) em seu livro-texto de física e química com cinco volumes, publicado em $1824 .{ }^{29}$ Albuquerque dedica uma seção, logo no início de sua obra, para discutir, com algum detalhe, a nomenclatura química, justificando que a química já possuía então "huma nomenclatura regular e systematica". No entanto, não chega a mencionar autor algum nesta seção, ao contrário de todas as outras partes de sua obra, que contam com citações abundantes a autores e artigos científicos.

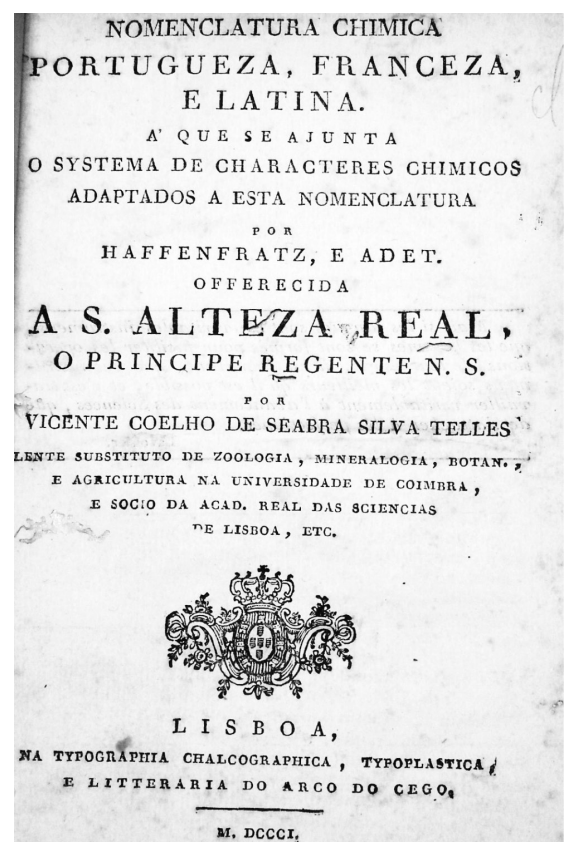

Figura 1. Página de rosto do livro em que Seabra Telles apresenta a nomenclatura em português

\section{A NOMENCLATURA TRADUZIDA PARA O PORTUGUÊS}

O livro de Seabra Telles conta com 121 páginas numeradas. Como epígrafe, no verso da folha de rosto da Nomenclatura... há uma longa citação de Lavoisier, mantida em francês:

Mas, se as línguas são verdadeiros instrumentos que os homens conceberam para facilitar as operações de suas mentes, é importante que estes instrumentos sejam os melhores possíveis, e tentar aperfeiçoá-los é realmente trabalhar para o avanço das ciências. ${ }^{30}$

Este fragmento pode ser encontrado na monografia que abre o livro Méthode de nomenclature chimique (viz. Tabela 1). 
Ao contrário do original francês e da tradução espanhola, em que o dicionário em si é acompanhado por longos textos sobre a filosofia da linguagem que fundamentou a criação da nova nomenclatura, Seabra Telles somente se utiliza de três páginas para apresentar sua introdução ao método de nomenclatura. Apenas se pode especular sobre as razões pelas quais Seabra Telles decidiu omitir essa monografia inicial de sua publicação. Enquanto Seabra Telles se restringiu a transcrever um único parágrafo, o tradutor espanhol logrou publicar a tradução completa da monografia de Lavoisier para o castelhano (Tabela 3).

Tabela 3. Organização geral do livro Nomenclatura chimica portugueza de Vicente Seabra Telles

\begin{tabular}{lc}
\hline Título da seção & Páginas \\
\hline introducção & não numeradas \\
Sinonímia portugueza & 1 a 20 \\
Sinonimie françoise & 21 a 39 \\
Diccionario portuguez, francez, latino para a nova & 40 a 121
\end{tabular}

nomenclatura chimica

Errata

sem número

Antes da introdução, há um primeiro parágrafo de apresentação com a usual saudação ao Príncipe Regente. Nesta parte, Seabra Telles deixa claro que reconhece a diferença do governo de João VI em relação aos anteriores no que concerne ao avanço das ciências, ao escrever que "estava reservada para [este] reinado [...] a glória de fixar esta época", em que "os costumes e as Sciencias marcham com passo igual, uniforme e rápido para a sua perfeição".

Após uma introdução de não mais de 3 páginas, Seabra Telles inicia o dicionário propriamente dito (Figura 2), com o total de 19 páginas - cada uma contendo cerca de 40 nomes antigos, seguidos dos termos correspondentes de acordo com a nova nomenclatura química, ambos em português.

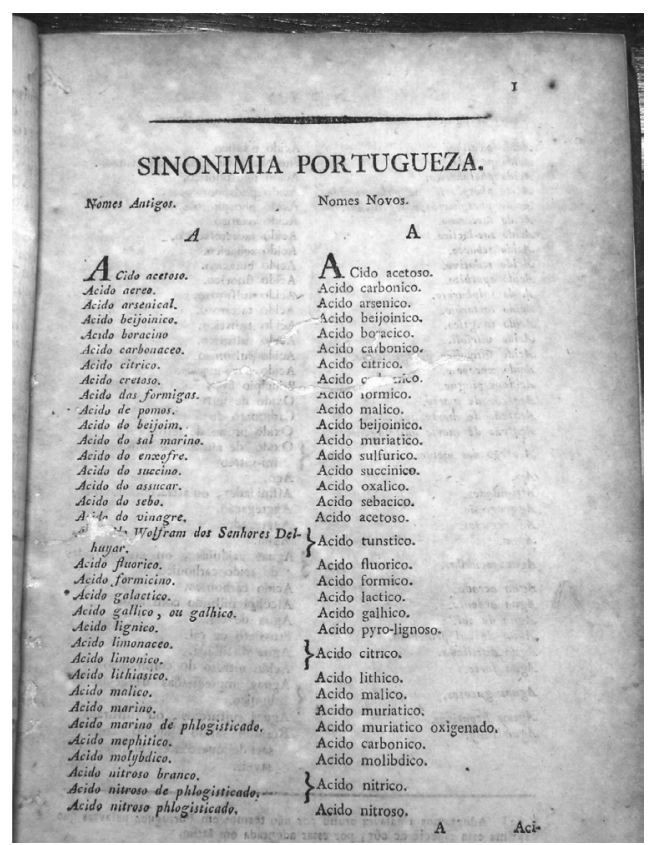

Figura 2. Primeira página da lista de 'nomes antigos' para as substâncias químicas e os respectivos 'nomes novos', de acordo com a nomenclatura da 'nova química'

As primeiras vinte páginas apresentam a lista alfabética das designações antigas das substâncias em português e os 'nomes novos', ou seja, os nomes de acordo com o novo sistema sendo proposto. É aqui que se aprende, por exemplo, que ‘ácido vitriólico’ deve passar a ser chamado de ácido sulfúrico.

Nessa lista, além de compostos e substâncias simples e até o que consideramos hoje algumas misturas, também foram incluídos conceitos. Encontram-se listados, por exemplo, afinidade, agregado, agregação, calcinação, combustão, flogisto, grafado com 'ph' no lugar do f. Por meio desses verbetes, aprende-se que calcinação deveria, a partir de então, ser substituída por oxidação; que a palavra combustão deveria ser abolida e, para descrever este fenômeno, se deveria referir a 'oxigenação com calor'. Quando menciona o flogisto, Seabra Telles faz questão de deixar claro que se trata de princípio 'hipotético', mas ainda referido como princípio inflamável. ${ }^{31}$

Nas vinte páginas seguintes, na seção do livro que denomina sinonimie françoise (sic), Seabra Telles nos apresenta a mesma lista alfabética de nomes antigos e nomes novos, mas ambos agora em francês. Já na terceira parte, que vai da página 40 até a página 121 , encontra-se uma nova lista das substâncias químicas, primeiro em português, depois em francês e, finalmente, em latim, na ordem alfabética dos nomes novos, na coluna à esquerda e, na coluna à direita, os nomes antigos ou a explicação do que se tratava, também em português, como no exemplo mostrado no Esquema 1. No final, encontram-se duas páginas e meia contendo errata e as respectivas correções.

$\left.\begin{array}{l}\text { Nitrato } \\ \text { Nitrate } \\ \text { Nitras, tis s.m }\end{array}\right\} \begin{aligned} & \text { Sal formado pela combinação } \\ & \text { do acido nítrico e as differentes } \\ & \text { bases térreas, alcalinas ou metálicas }\end{aligned}$

Esquema 1. Na terceira e última parte da Nomenclatura chimica portugueza são listados os termos em latim

Na introdução da Nomenclatura..., a necessidade da normatização e unificação dos termos usados nas ciências químicas é justificada, lembrando que os portugueses se utilizavam indistintamente das desinências latina e francesa nos seus escritos, e que sem a adoção de uma única regra, a química perderá "a sua elegancia, e belleza, e será monstruosa, escura, e inutil para o seu fim”. É assim que, logo nas primeiras páginas, Seabra Telles se empenhou em justificar suas escolhas, afirmando que iria seguir

geralmente a etymologia latina, e a desinencia portugueza, não somente porque o nosso idioma tem mais analogia com ella, como porque a dicçao latina he hoje geralmente seguida em todas as obras chimicas, e phisicas, que recentemente se tem publicado em lingua latina. ${ }^{32}$

Ainda insistindo no mesmo ponto mais adiante, Seabra Telles volta a defender que se adote, para a língua portuguesa, uma nomenclatura mais próxima do latim, "com quem a lingua portugueza tem mais analogia, do que com a francesa."

Aqui se pode talvez detectar uma contradição. Primeiro o autor afirma que vai seguir a desinência portuguesa, depois diz que seguirá a desinência latina. Não se pode descartar a ocorrência de um lapso, e que, na verdade, tencionava referir-se às desinências latinas, pois esta afirmação é seguida do exemplo pormenorizado de como procedeu na tradução dos compostos de fósforo mostrados na Tabela 4.

Nessa tabela, deve-se notar que a tendência geral é a quantidade de oxigênio diminuir quando se avança caso a caso ou, usando termos da época, a saturação com oxigênio seria máxima no primeiro caso, e tende a diminuir nos casos subsequentes. Seabra Telles explica, no seu texto introdutório da tradução do Méthode para português que, no primeiro caso (mostrado na Tabela 4), a terminação em português 
Tabela 4. Comparação entre os termos escolhidos para o português a partir do francês

\begin{tabular}{ccccc}
\hline Caso & Méthode (1787) & S.Telles (1801) & em latim & fórmula hoje \\
\hline $1^{\circ}$. & Acide phosphorique & Ácido fosfórico & Acidum phosphoricum & $\mathrm{H}_{3} \mathrm{PO}_{4}$ \\
$2^{\circ}$. & Acide phosphoreux & Ácido fosforoso & Acidum phosphorosum & $\mathrm{H}_{2} \mathrm{PO}_{3}$ \\
$3^{\circ}$. & Phosphate & fosfato & phosphas & $\left(\mathrm{PO}_{4}\right)^{3-}$ \\
$4^{\circ}$. & Phosphite & fosfito & phosphis & $\left(\mathrm{PO}_{3}\right)^{2-}$ \\
$5^{\circ}$. & Phosphure & fosforeto & phosphoretum & $\mathrm{P}^{3-}$ \\
\hline
\end{tabular}

seria "ico: no segundo caso o mesmo nome radical [fosfor] terminará em oso: no terceiro caso terminará em ato: no quarto acabará em ito; e no quinto caso em eto." 33

Ao traduzir os nomes dos gases do francês para o português, mostrados na Tabela 5, também podemos constatar sua preferência pela aproximação com o latim. Os sufixos escolhidos por Seabra Telles para os nomes com que batizou dois tipos de gases diferentes, cuja identidade estava se estabelecendo naquela época, ou seja, o ar inflamável e o ar deflogisticado, refletem essa escolha de aproximar-se mais do latim do que da língua francesa. O elemento constitutivo - gène em francês geralmente é traduzido para o português como '-geno', ${ }^{34}$ como na palavra 'patógeno', por exemplo.

Tabela 5. Exemplos da opção pela semelhança com o latim nos nomes propostos por Seabra Telles

\begin{tabular}{cccc}
\hline nome anterior & $\begin{array}{c}\text { francês } \\
(\text { Méthode }, 1787)\end{array}$ & $\begin{array}{c}\text { português } \\
(\mathrm{S} . \text { Telles, 1801) }\end{array}$ & latim \\
\hline ar inflamável & hidrogène & hydrogenio & hydrogenium \\
ar deflogisticado & oxigène & oxigenio & oxygenium \\
\hline
\end{tabular}

O dicionário Houaiss discute brevemente o aportuguesamento da palavra oxigène, fazendo um paralelo com o espanhol, mas ignora o trabalho de Vicente Seabra Telles, e atribui o estabelecimento, em português, da forma paroxítona 'oxigênio' — em detrimento da proparoxítona 'oxígeno'- à resistência popular:

de início, essa série proparoxítona deve ter sido mal recebida para usos populares, de tal modo que um vocábulo como o francês oxigène teria gerado dúvida no aportuguesamento ou espanholizamento — do que dá prova a solução portuguesa oxigênio e o espanhol oxígeno (mais conforme com o étimo). ${ }^{35}$

O Houaiss reafirma que oxígeno seria mais próximo do original, ignorando, entretanto, que o estabelecimento da forma oxigênio foi uma escolha deliberada e justificada feita por Seabra Telles no início do século XIX e que encontrou aceitação, inicialmente, entre os homens de ciência e, depois, foi devidamente incorporada ao vernáculo.

A introdução dos sufixos na nomenclatura dos compostos, como explica Beretta, ${ }^{36}$ foi uma inovação revolucionária na sintaxe da linguagem química, pois além de unificar e dar nomes iguais às substâncias formadas a partir de um reagente de partida em comum, também indicava o grau de saturação em relação ao oxigênio. A variação no sufixo denotava uma variação na quantidade de matéria presente na substância química. Essa inovação respondia aos anseios de Lavoisier de transformar a linguagem numa ferramenta analítica de certo modo à maneira dos matemáticos, como escreveu no ensaio introdutório ao Méthode de nomenclature chimique:

As línguas não são destinadas apenas, como normalmente se pensa, a comunicar por [meio de] sinais, ideias e imagens: são, além disso, verdadeiros métodos analíticos, com o qual nós procedemos do conhecido para o desconhecido e, em certa medida, na [mesma] maneira dos matemáticos. ${ }^{37}$

Com a ajuda da Tabela 6, é possível comparar a nomenclatura em português e em francês com os termos latinos para compostos de enxofre. Nessa época, sabia-se que, no ácido sulfúrico, o enxofre se encontra saturado com oxigênio, ao passo que, no ácido sulfuroso, o enxofre se combina com uma quantidade limitada de oxigênio. 'Sulfato' foi o nome dado aos sais formados a partir do ácido sulfúrico, enquanto que foram denominados 'sulfitos' todos os sais formados a partir do ácido sulfuroso. 'Sulfeto' foi o nome genérico para um composto de enxofre livre de oxigênio.

Ao realizar essas escolhas, Seabra Telles optou, na maioria das vezes, pela semelhança com o latim, em detrimento do francês. Nos outros casos, os termos em português são quase iguais aos franceses. Assim é que acidum sulphurosum do latim tornou-se 'ácido sulfuroso' em português, embora seja acide sulfureux em francês.

Como mostra a Tabela 6, o espanhol Pedro Gutierrez Bueno, que traduziu o livro de Lavoisier para o castelhano, fez escolhas semelhantes: "en vez de la palabra francesa sulphure, pongo sulfurete, que tiene mas analogía con la latina sulphuretum". ${ }^{38}$ Como o livro de Bueno foi publicado 12 anos antes, é provável que Seabra Telles o tenha lido e por ele tenha sido influenciado, seguindo o exemplo espanhol, apesar de não dar nenhuma indicação nesse sentido em sua obra.

\section{CONSIDERAÇÕES FINAIS}

Muitos dos termos da Química que utilizamos na língua portuguesa até hoje e durante os últimos dois séculos foram criados pelo químico brasileiro Vicente Seabra Telles ao traduzir do francês para o português o livro seminal do grupo de Lavoisier, que estabeleceu as bases da nomenclatura da nova química criada no final do século

Tabela 6. Comparação entre os termos escolhidos para o português e o castelhano a partir do francês e do latim

\begin{tabular}{ccccc}
\hline Caso & em latim & Méthode (1787) & Bueno (1788) & Seabra Telles (1801) \\
\hline $1^{\circ}$. & Acidum sulphuricum & Acide sulfurique & Ácido sulfúrico & Ácido sulfúrico \\
$2^{\circ}$. & Acidum sulphurosum & Acide sulfureux & Ácido sulfuroso & Ácido sulfuroso \\
$3^{\circ}$. & sulphas & sulfate & sulfate & sulfato \\
$4^{\circ}$. & sulphis & sulfite & sulfite & sulfito \\
$5^{\circ}$. & sulphuretum & sulfure & sulfureto & sulfureto \\
\hline
\end{tabular}


XVIII. A maneira como nos referimos aos gases cujos nomes terminam com o sufixo '-gênio', por exemplo, foi uma decisão determinada por Vicente Seabra Telles para torná-los mais semelhantes com os termos cognatos em latim. É por causa dessa decisão expressa de Seabra Telles que hoje dizemos em português oxigênio, em lugar de oxígeno, que seria a tradução mais direta do termo original em francês, que é oxigène, e seguindo o mesmo mecanismo de termos semelhantes, como patógeno, também oriundo do francês.

A elite intelectual luso-brasileira acompanhava atentamente os inúmeros debates científicos e filosóficos que se desenrolavam nos países centrais da Europa, apreendendo devidamente e dialogando com as mais recentes teorias científicas que surgiam durante o auge do período do Iluminismo. Os homens dedicados à ciência no Império Português - muitos deles nascidos no Brasil — se envolveram ativamente na circulação internacional de textos científicos, fazendo a conexão entre as línguas dos países centrais da Europa com o português usado na criação de conhecimento e na difusão da produção científica mais recente.

\section{AGRADECIMENTOS}

Pela gentil permissão de fotografar o livro de Seabra Telles e frequente acolhida agradeço ao Real Gabinete Português de Leitura do Rio de Janeiro. Devo também agradecer à Profa. L. Kury (COC-FIOCRUZ) pelas aulas de história durante meu pós-doc e ao Prof. C. E. B. de Sousa (UENF) pela cuidadosa leitura crítica.

\section{REFERÊNCIAS E NOTAS}

1. Como explica T. Hankins (Science and the Enlightenment, Cambridge Press: New York, 2007, p. 81), os homens de ciência contemporâneos do Iluminismo não somente tinham consciência de que vivenciavam uma revolução na química, como a haviam mesmo antevisto. Em 1773, Lavoisier anotava que o seu trabalho sobre a química dos gases estaria "fadado a provocar uma revolução no terreno da física e da química" (Apud Filgueiras, C. A.; Quim. Nova 1995, 18, 219).

2. http://plato.stanford.edu/archives/fall2010/entries/enlightenment/, acessada em Fevereiro 2013 (Bristow, W. Em The Stanford Encyclopedia of Philosophy; Zalta, E. N., ed.).

3. http://philosophy.eserver.org/kant/what-is-enlightenment.txt, acessada em Fevereiro 2013.

4. Boschi, C. Em Política, nação e edição o lugar dos impressos na construção da vida política: Brasil, Europa e Américas nos séculos XVIII-XX; Dutra, E. R. de F.; Mollier, J-Y., eds.; Annablume: São Paulo, 2006, p. 495-510.

5. de Morveau, L. G.; Lavoisier, A.; Bertholet, C.; de Fourcroy, A.; Méthode de nomenclature chimique, Cuchet: Paris, 1787.

6. Lavoisier, A. Em Méthode de nomenclature chimique; de Morveau, L. G.; Lavoisier, A.; Bertholet, C.; de Fourcroy, A., eds.; Cuchet: Paris, 1787, p. 24.

7. Lavoisier, A. Em ref. 6, p. 2.

8. Luna, F. J.; Kury, L.; Ambix 2012, 59, 218.

9. de Morveau, L. G.; Journal de Physique 1782, 19, 382.

10. Lavoisier, A. Em ref. 6, p. 6.

11. Lavoisier, A. Em ref. 6, p. 15.
12. Lavoisier, A. Em ref. 6, p. 16.

13. Partington, J. R.; A History of Chemistry, Macmillan: London, 1962, vol. 3, p. 97.

14. Partington, J. R. Em ref. 13.

15. Crosland, M.; Historical Studies in the Language of Chemistry, Harvard Univ. Press: Cambridge, 1962, p. 191.

16. Bueno, P. G., trad.; Método de la nueva nomenclatura química, Don Antonio de Sancha: Madrid, 1788.

17. St. John, J., trad.; Method of Chymical Nomenclature, G. Kearsley: London, 1788.

18. Dobson, T.; Encyclopedia; or, a dictionary of arts, sciences, and miscellaneous literature, Thomas Dobson: Philadelphia, 1798, vol. IV, p. 597.

19. Lundgren, A.; Osiris, $2^{\text {nd }}$ series, 1988, 4, 162.

20. Varnhagen, F. A.; Revista do Instituto Histórico e Geográfico Brasileiro 1847, 9, 261.

21. Filgueiras, C. A. L.; Quim. Nova 1985, 8, 263.

22. Cf. Estatutos da Universidade de Coimbra, Regia Officina Typografica: Lisboa, 1773, livro III, p. 341-374.

23. Gouveia, A. J. A.; 'Breve Notícia de Apresentação'; Em Seabra Telles, V. C., Elementos de Chimica (Reprodução fac-similada); Univ. de Coimbra: Coimbra, 1985, p. VII-XII.

24. Filgueiras, C. A. L.; NTM-Schriftenr. Gesch. Naturwiss., Technik, Med. 1990, 27, 27.

25. de Moraes, R. B.; Bibliografia brasileira do período colonial, IEB-USP: São Paulo, 1969, p. 378.

26. http://www.spq.pt/docs/Biografias/Vicente $\% 20$ Coelho $\% 20$ de $\% 20$ Seabra\%20\%20port.pdf, acessada em Fevereiro 2013.

27. Costa, A. M. A.; Primórdios da ciência química em Portugal, Instituto de Cultura e Língua Portuguesa, Ministério da Educação: Lisboa, 1984.

28. de Seabra, V. C.; Elementos de chimica, Real Officina da Universidade: Coimbra, 1788, parte I, p. 56.

29. de Albuquerque, L. da S. M.; Curso elementar de physica e de chymica offerecido aos alumnos destas sciencias no Real laboratorio chymico da Moeda, Tipografia de António Rodrigues Galhardo: Lisboa, 1824, tomo III.

30. Lavoisier, A. Em ref. 6, p. 8.

31. Também menciona aqui um 'princípio mercurial', devido a Beccher (sic).

32. Telles, V. C. de S. S.; Nomenclatura chimica portugueza, franceza, e latina, Typographia Chalcographica, Typoplastica e Litteraria do Arco do Cego: Lisboa, 1801, p. II.

33. Telles, V. C. de S. S.; Em ref. 32, p. III.

34. No verbete '-geno' Em Houaiss, A.; Villar, M. de S.; Dicionário Houaiss da Língua Portuguesa; Objetiva: Rio de Janeiro, 2001, p. 1443, explicase que este sufixo dá noção de 'nascimento, origem, descendência, raça', em compostos do século XIX em diante; a relação é de todo estreita com os comp. em '-geno', que, transmitidos por via do grego ou do latim, geravam proparoxítonos puros em -ógeno ou -ígeno, respectivamente.

35. Houaiss, A.; Villar, M. de S.; Dicionário Houaiss da Língua Portuguesa, Objetiva: Rio de Janeiro, 2001, p. 1442.

36. Beretta, M.; The Enlightenment of matter: the definition of chemistry from Agricola to Lavoisier, Watson Publishing: Canton, 1993, p. 210.

37. Lavoisier, A. Em ref. 6, p. 6.

38. Bueno, P. G. Em ref. 16, p. 5. 